\title{
A CONSTRUÇÃO DE CONCEITOS DE GÊNERO, CULTURA E PROCESSO AVALIATIVO NO ENSINO DE LÍNGUA ESTRANGEIRA
}

\author{
Ângela L. F. Ferreira \\ Márcia J.Dias de Aguiar \\ Marcos Gustavo Richter
}

\section{RESUMO}

Este artigo focaliza experiências teórico-práticas que estão sendo desenvolvidas com uma acadêmica professora de um Curso de Língua Estrangeira. $O$ trabalho tem como suporte metodológico as concepções da pesquisa-ação, as quais enfatizam um processo reflexivo e crítico das práticas pedagógicas do professor. Mais precisamente, buscar-se-á operacionalizar a teoria de gêneros e cultura no contexto da docente acadêmica, bem como analisar em que medida a aluna professora articula seus conceitos de avaliação com a prática de sala de aula.

\section{INTRODUÇÃO}

No ensino de língua estrangeira (LE) temos obviamente como meta uma aprendizagem de qualidade. Porém nem sempre isso é possível, em função dos mais variados problemas que surgem diante dos professores, o que torna o ensino de LE uma atividade árdua e desafiante. Nesse contexto, a reflexão sobre as práticas pedagógicas e a mudança decorrente tornam-se elementos fundamentais no processo de constituição docente.

Dentre as várias estratégias que podem auxiliar significativamente o processo de ensino e aprendizagem de LE, destaca-se a articulação didática língua-gêneroscultura, potencializada pela metodologia de pesquisa-ação (PA). Mais especificamente a PA associa a reflexão metódica sobre a prática de ensino a um trabalho grupal colaborativo. Para tanto, começa-se por discriminar um problema ou algo a ser aprimorado em um contexto específico de ensino. Em reuniões periódicas são levantadas alternativas para solucionar tal problema ou melhorar tal abordagem. Nesse sentido, hipóteses são levantadas e posteriormente ratificadas, ou não, no ambiente de sala de aula. Ciclicamente esse processo se desenrola até resultar em mudanças até certo ponto esperadas e/ou adequadas. Em função disso, estar em sala de aula, estar em contato com os alunos, é realmente essencial para o grupo de trabalho, na medida que somente em contextos reais problemas pedagógicos podem ser resolvidos ou amenizados, bem como propostas de mudança postas à prova. 
A partir disso, este artigo pretende apresentar resultados parciais sobre um trabalho de formação inicial de professores que vem sendo desenvolvido com uma acadêmica de uma universidade de Santa Maria, atuando como professora em um curso de inglês promovido extensionalmente. Mais precisamente, busca-se: a) operacionalizar conceitos de gênero e cultura e de avaliação na prática de sala de aula; b) verificar como as teorias informais da acadêmica influenciam sua conduta docente; e c) investigar como através das leituras, da reflexão sobre seu ensino, sua ação e concepções no seu ambiente de ensino vêm se modificando ou resistindo à mudança.

\title{
2. CONCEPÇÕES TEÓRICO-PRÁtICAS PARA O ENSINO DE GÊNERO E CULTURA
}

Para implementar modificações didáticas centradas no ensino de gênero vinculado à cultura, as percepções teóricas que a acadêmica-docente já tem a respeito desse tema constituem o ponto inicial do percurso do grupo reflexivo. À primeira vista as concepções do trabalho com gêneros da acadêmica não se mostravam muito consistentes teoreticamente. Ao analisarmos um dos diários de aula da acadêmica verificamos sua opinião a respeito:

\begin{abstract}
Eu não abordei o texto introdutório como gênero, pois, com sinceridade, eu não tenho (não conheço) uma abordagem que considere interessante e, até mesmo, "de conteúdo" (no sentido de boa) para apresentar aos alunos... Na minha opinião, os alunos ficam um pouco desinteressados se eu começo a indagá-los sobre quem seria o público alvo para aquele texto, com que propósito ele foi escrito.
\end{abstract}

Verifica-se aqui, claramente, superficialidade dos conceitos da alunaprofessora a respeito de gêneros e, além disso, uma predisposição algo aversiva de se trabalhar com os mais variados tipos de textos de uma forma mais crítica e detalhada. Em outras palavras, suas crenças negativas a impedem de se empenhar por uma maneira mais produtiva de trabalhar com os textos. Ressalte-se que a aluna em questão já havia trabalhado anteriormente com gêneros e sua experiência não foi positiva, a nosso ver, por falta de orientação e apoio teórico na época, o que parece ter contribuído para desmotivá-la em relação a essa metodologia. Isso vai ao encontro do que Rottava e Freudenberger (2002:85), mencionando Johnson, falam a respeito 
das crenças dos professores: "As crenças possuem, portanto, um componente afetivo, um cognitivo e um comportamental e, influenciam, dessa forma, o que os professores sabem, sentem, fazem e como interpretam seu fazer." Complementando essa declaração, as autoras (idem: 86) declaram que: "As crenças têm origem nas experiências e são pessoais, intuitivas e na maioria das vezes, implícitas. Dessa forma, as crenças não são apenas conceitos cognitivos, mas são socialmente construídas sobre experiências e problemas pessoais". Vale mencionar que as crenças, originando-se em grande parte de experiências concretas, apresentam caráter contextual e flexível, sendo portanto passíveis de mudança (embora esta possa se revelar difícil).

A partir desse panorama inicial, foi problematizada a relevância do estudo de gêneros, a perspectiva adotada e sua aplicabilidade em sala de aula, bem como destacados os conceitos relevantes para efetivar a aquisição de uma LE em todas as suas dimensões. Hyon (1996:693) destaca as três tradições na pesquisa sobre gêneros a serem conhecidas para, a partir dos objetivos estipulados no ensino da LE, buscar um reforço teórico e metodológico para a consecução de uma prática didática desejável em sala de aula:

\begin{abstract}
A investigação revela que ESP [inglês para fins instrumentais] e a pesquisa de gêneros australiana fornecem aos instrutores de ESL percepções das características lingüísticas de textos escritos, bem como orientações úteis para apresentar essas características em sala de aula. O estudo da Nova Retórica, por outro lado, oferece aos professores de língua perspectivas completas sobre os contextos institucionais ao redor dos gêneros acadêmicos e profissionais e as funções que esses gêneros têm dentro desses ambientes. ${ }^{1}$
\end{abstract}

Os objetivos estabelecidos no contexto de sala de aula são fundamentais na escolha e delimitação de dada concepção de gênero. No nosso caso, utilizamos o gênero como uma forma de trazer a cultura estrangeira para ser analisada, discutida, comparada com a nossa no ambiente de sala de aula. Além disso, o gênero e seu conteúdo são utilizados como um background de informações culturais necessárias para a discussão, focalizando, assim, a oralidade, a conversação conforme as

\footnotetext{
${ }_{1}^{1}$ Original em inglês: The investigation reveals that ESP and Australian genre research provides ESL instructors with insights into the linguistic features of written texts as well as useful guidelines for presenting these features in classrooms. New rethoric scholarship, on the other hand, offers language teachers fuller perspectives on the institutional contexts around academic and professional genres and the functions genres serve within these settings.
} 
necessidades referidas por esses alunos no início do semestre, ao responderem a análise de necessidades.

A prioridade, nesta opção de trabalho, é abordar a cultura de uma LE utilizando os gêneros como materiais que revelam ações de linguagem impregnadas culturalmente, visto que a relação entre gênero e cultura é muito forte. Kramsch (1998:62) enfatiza essa relação ao dizer que "um gênero em uma perspectiva sóciocultural é sempre dependente de ser percebido como tal dentro de um contexto de situação ou cultura específica". ${ }^{2}$ Segundo Moran (2001) a estrutura cultural dos saberes (Knowings) é uma maneira eficaz de se trabalhar aspectos culturais de acordo com as necessidades verificadas em aula. Para ele (idem:15), uma experiência cultural pode ser concebida a partir de quatro tipos de saberes que podem ser trabalhados conectados, ou individualmente, dependendo dos propósitos do professor. Os saberes são knowing about, knowing how, knowing why e knowing oneself. Especificando simplificadamente cada um deles, temos que o "saber sobre" (Knowing about) refere-se à aquisição, até certo ponto, passiva dos alunos a respeito da outra cultura, ou seja, eles lerão ou ouvirão informações, eles aprenderão algo sobre a nova cultura. O "saber como" (Knowing how) leva-os a aprenderem na prática aspectos culturais em que seja muito importante fazer ou operar algo, fisicamente falando, que seja visto na outra cultura. O "saber por quê" (Knowing why) envolve a análise, discussão, desenvolvimento de percepções a respeito de crenças valores e atitudes que permeiam o povo estrangeiro. Para o autor (2001:16) o "saber por quê" envolve "habilidades para investigar, analisar e explicar os fenômenos culturais que os alunos encontram, os quais necessariamente envolvem uma comparação com sua própria cultura e com eles mesmos". ${ }^{3}$

E por último, temos o "conhecer a si mesmo" (knowing onself) em que são mais destacadas as características da cultura do aluno, seus valores, opiniões, sentimentos, comportamentos. Isso pode ocorrer através da comparação entre a minha cultura e a do outro, mas sempre destacando a minha cultura. Eles refletem sobre si mesmos a partir da análise do outro.

\footnotetext{
2 Original em inglês: ... a genre in a sociocultural perspective is always dependent on being perceveid as such within a specific context of situation or culture.

${ }^{3}$ Original em inglês: ...skills in probing, analyzing, and explainig the cultural phenomena learners encounter, which necessarily involves a comparison with their own culture and themselves.
} 
Acreditamos que as perspectivas de Knowing why e oneself sejam propicias para análise cultural no ambiente de ensino da acadêmica docente. Atenção especial vem sendo dada as discussões e às reflexões oportunizadas pela leitura de gêneros que reportem cultura, abordados em aula. Pensamos que nessas condições a concepção de gênero mais relevante seja a da Nova Retórica Americana que focaliza os textos em uma perspectiva contextual e social. Hyon (1996:696) destaca o ponto de vista da Nova Retórica, ao mencionar que

Os estudiosos de gêneros nessas áreas diferenciaram-se dos estudiosos no $\mathrm{ESP}$, visto que eles focalizaram mais nos contextos situacionais, nos quais os gêneros ocorrem do que nas suas formas e eles têm dado ênfase especial aos propósitos sociais ou ações que esses gêneros desempenham dentro dessas situações. ${ }^{4}$

Sendo assim, é muito importante que a acadêmica tenha um apoio teórico tanto de gênero como de cultura para desenrolar suas atividades eficazmente no contexto de ensino.

Recursos teóricos oferecidos pela linha interacionista sócio-discursiva têm-se mostrado viáveis e de grande proveito no ensino de inglês. Segundo Marcuschi (2002:22),

Esta visão segue uma noção de língua como atividade social, histórica e cognitiva. Privilegia a natureza funcional e interativa e não o aspecto formal e estrutural da língua... Nesse contexto teórico, a língua é tida como uma forma de ação social e histórica que, ao dizer, também constitui a realidade, sem contudo cair num subjetivismo ou idealismo ingênuo.

Essa concepção de língua encara os gêneros como uma forma de agir no mundo e recriá-lo. Fortemente associada ao gênero se encontra a cultura, que particulariza contextualmente os gêneros. Para Marcuschi (2002:22), "é neste contexto que os gêneros textuais se constituem como ações sócio-discursivas para agir sobre o mundo e dizer o mundo, constituindo-o de algum modo".

A partir dessas declarações é possível perceber o conjunto de relações que precisam ser explicitadas em sala de aula ao se conceber o gênero em uma perspectiva de ação social. A forma, neste caso, é relevante, mas não o foco principal como em outras áreas de pesquisa genérica. Ao se trabalhar com determinado texto

\footnotetext{
${ }^{4}$ Original em inglês: Genre scholars in these areas have differed from those in ESP as they have focused more on the situational contexts in which genres occur than on their forms and have placed special emphasis on the social purposes, or actions, that these genres fulfil within these situations.
} 
torna-se oportuno: a) remeter ao contexto sócio-cultural do escritor, seus valores e crenças, bem como ao ambiente social do leitor e suas similaridades e/ou diferenças com o contexto analisado; b) analisar o conteúdo do texto e os participantes veiculados nele, seus valores e ideologias, bem como as funções sociais daquele gênero; c) trabalhar a relevância desse conteúdo cultural para o leitor que no próprio ato de leitura interagiu via texto com o escritor na medida em que aceitou, refletiu, questionou, criticou, considerou o que leu; e d) estimar a relevância daquele texto e seu conteúdo no contexto do próprio escritor que certamente usou o gênero para agir socialmente, comunicar-se com os demais indivíduos de seu ambiente sócio-histórico.

Do que expusemos, fica clara a importância de um estudo mais aprofundado desses aspectos pelo professor "in service" e também pelo professor em formação, no que tange a uma dada teoria de gêneros e cultura, pois, em função disso, eles desenvolverão as premissas para um processo de aprendizagem mais produtivo para a vida real dos alunos, na medida em que, através da aquisição de uma segunda língua, aquisição de conhecimento cultural e dos gêneros e suas funções de forma crítico-reflexiva, o público-alvo pode instrumentalizar-se para agir melhor socialmente.

Relembrando que inicialmente a crença dessa acadêmica em relação ao trabalho com gêneros era negativa, um dos nossos objetivos era investigar se suas concepções e práticas acabaram refletindo mudanças após entrar em contato com a pesquisa-ação, após refletir sobre sua didática de sala de aula. Além disso, procuramos avaliar se as leituras teóricas sobre gênero e cultura, o trabalho colaborativo na construção das aulas vem fornecendo indícios de contribuir para uma melhor performance docente.

Após alguns meses de trabalho em PA, percebemos que a opinião da acadêmica tinha mudado e que revelava interesse em aprender sobre o o tópico "gêneros" com o intuito de aprimorar sua metodologia, como podemos acompanhar no fragmento de diário abaixo:

Ao ler os artigos que $M$. indicou, eu me dei conta da importância da abordagem de gêneros em sala de aula. É necessário fazer com que o aluno tenha consciência do que, como e pq ele lê. Aprendi que diferentes gêneros sendo trabalhados em sala de aula proporcionam ao aluno uma base para poder refletir e também criticar as maneiras com as quais o conhecimento e as informações são construídas e organizadas na língua em que eles estão estudando. Por enquanto, tenho noção disso, mas tenho muito mais interesse em saber como abordarei o ensino de gênero, que estratégias posso usar ao trabalhar uma crítica de filme, por exemplo. 
$\mathrm{Na}$ primeira avaliação bimestral a acadêmica escolheu um editorial para trabalhar com questões de interpretação e língua. Ao corrigir a prova com os alunos em aula, ela tentou abordar o texto de forma mais pormenorizada e crítica, visando uma abordagem de leitura que considerasse o texto como uma forma de ação social. Em seu diário, ela comentou, a respeito dessa prática datada:

\begin{abstract}
Nesta aula eu tentei abordar o texto da prova (aula passada) como gênero. Eu não tinha idéia de como fazer para tratar o texto como gênero, pois nunca havia trabalhado com editoriais, mas de acordo com as leituras que fiz sobre como trabalhar o gênero num contexto social, eu tentei questionar os alunos sobre os próprios hábitos deles em relação àquele gênero (...) Essa parte de questões de "pre-reading" foram bastante proveitosas, pois os alunos participaram e deram exemplos. Alguns mencionaram os diferentes tipos de editorias em cada revista, o que me deixou contente, pois vi que eles tinham uma boa idéia em relação aquele assunto (...) Gostaria de ter mais leituras sobre como trabalhar com a estrutura deste gênero (e outros tbm) e como abordá-los, pois o que eu fiz, foi no que eu pensei ser relevante.
\end{abstract}

Essa passagem indicia que a acadêmica aos poucos está operacionalizando em sua prática o que adquire na teoria e nas discussões teórico-práticas realizadas. E o mais importante a destacar, a esta altura do processo, é o interesse e motivação para aprender e melhorar a prática pedagógica, com benefícios educativos para ambas as partes, docente e discente.

\title{
3. CONSIDERAÇÕES SOBRE O PROCESSO AVALIATIVO NO ENSINO DE LE
}

Quanto à questão da avaliação, o trabalho que vem sendo desenvolvido iniciouse com a investigação de quais eram os conceitos que a acadêmica-professora possuía a respeito desse aspecto, e qual a relação desses conceitos com a sua prática no processo pedagógico.

Através da reflexão sobre a sua experiência de ensinar e avaliar esperamos diagnosticar os problemas relacionados à avaliação que ela possa estar enfrentando, e de forma conjunta e cooperativa, conforme os princípios postulados pelo método de pesquisa-ação, esclarecer e buscar a resolução de tais problemas.

Durante as reflexões quinzenais organizadas de acordo com os sete ciclos que compõem o semestre letivo do curso ministrado pela acadêmica professora pudemos perceber que ela entende a avaliação como um procedimento dissociado do processo 
de aprendizagem, que só deverá acontecer no final de cada bimestre, em forma de prova escrita, prova de leitura e de compreensão auditiva, ficando a produção oral em segundo plano.

As concepções da acadêmica sobre o processo avaliativo são compreensíveis considerando que ela tem como parâmetro a sua experiência como aluna do curso de graduação em Letras, no qual a maioria dos professores, como em grande parte das instituições de ensino do país, usa a avaliação como forma de controle e seleção dos alunos, e que é realizada somente no final do bimestre ou semestre, sem a observação do aspecto da continuidade. Tal comportamento pode ser atribuído a uma escassa formação pedagógica que leva os novos professores a recorrer a modelos de avaliação utilizados pelos seus próprios professores quando eram alunos.

Outro aspecto que poderia ser responsável por essa postura dos professores, principalmente de $2^{\circ}$ e $3^{\circ}$ graus, seria, de acordo com Hoffmann (1998:76-7), a perpetuação de cinco mitos que envolvem a avaliação e que seriam responsáveis pela evasão e as reprovações:

Mito 1: A qualidade dos cursos diminui quando a maioria dos alunos é promovida. Os cursos mais sérios são os que mais reprovam.

Mito 2: É impossível utilizar-se conceitos ou outras formas de registro na análise de desempenho de um estudante universitário. Somente o sistema de atribuições de notas e cálculo de média é justo e preciso na aferição da aprendizagem dos estudantes.

Mito 3: Provas finais extensas e sobretudo objetivas são os instrumentos mais eficazes para verificar o domínio do conhecimento.

Mito 4: Não se pode admitir que um estudante universitário cometa qualquer erro! Que profissional se estará formando?

Mito 5: A avaliação é uma exigência do sistema que se cumpre rigorosamente. Embora arbitrária e controladora, é um mal necessário!

Analisando a situação de forma objetiva, facilmente podemos desmistificar esses mitos que povoam a realidade escolar. Se o papel do professor é ensinar, melhor seria o curso e mais competente seria ele se mais alunos atingissem os objetivos esperados e não o contrário. 
Considerando que o aluno pode colar ou estudar somente para a prova, a nota não pode ser considerada como um instrumento justo para medir o seu conhecimento, ou ainda pode acontecer do aluno, em um determinado conteúdo, tirar 90 e, em outro, tirar 50 e conseguir no final a média 70. Por isso, não deveria ser a média, mas, sim, um mínimo de conteúdos aprendidos o critério para a aprovação. (Luckesi,1999:80).

A crença de que a prova quanto mais extensa mais eficiente se torna é improcedente, porque o tamanho da prova não significa absolutamente eficiência em verificar conteúdos. As provas extensas e com problemas de elaboração são cansativas e, muitas vezes, são prejudiciais ao aluno exatamente por isso, pois, antes de concluí-la, ele já está exausto. Isso pôde ser verificado no diário da acadêmica professora quando ao realizar a primeira avaliação os alunos reclamaram da extensão da prova, impedindo sua realização completa: "Os alunos reclamaram, pois a prova estava extensa (o texto era um pouco grande, eu reconheço)...”.

Provas objetivas podem ser eficientes, mas tiram a oportunidade de o aluno demonstrar de outra forma o que sabe e também mostrar quando sabe muito mais do que foi pedido. A vantagem de usar mais de um tipo de instrumento para avaliar é exatamente o fato de dar ao aluno e ao professor informações mais significativas e mais abrangentes a respeito do aproveitamento do aluno.

Cometer erros faz parte do processo de aprender, na opinião de autores como Hoffmann (2000:65) e Luckesi (1999:57). Não somente nas escolas ou na universidade, mas em qualquer aspecto da vida, todos estamos sujeitos a errar. Então, o ideal seria aprender com os erros. O professor que não admite o erro nos seus alunos está tirando-lhes oportunidades de aprendizagem.

A avaliação é realmente uma obrigação burocrática, uma vez que, no final de cada semestre, o professor tem que apresentar à secretaria as notas dos alunos. Mas ela não precisa ser um "mal necessário"; ela pode e deve ser um "bem necessário" a todos, inclusive ao professor e a instituição, se usada com o objetivo de proporcionar o crescimento do aluno como profissional em formação, do professor em busca da crescente competência e da instituição para promover condições de que os objetivos do professor e do aluno se concretizem.

Usada de forma autoritária e somente para medir resultados, a avaliação é capaz de acarretar vários danos ao aluno. Antes da avaliação, vem a angustia, a 
ansiedade e o nervosismo causados pela insegurança a respeito do que vai ser avaliado e do medo da reprovação. Depois da avaliação, vêm a decepção a frustração ao não haver conseguido um bom resultado (ou a aprovação) e, o que é pior, a certeza de que aqueles conceitos ou notas são definitivos.

A avaliação, de acordo com Hoffmann (1998:39) deveria ser tratada como um processo continuo que utiliza variados instrumentos com a intenção de verificar o que não foi aprendido, não só para dar uma nota ou conceito, mas, essencialmente, para retomar os objetivos que não foram atingidos, privilegiando sempre o aspecto qualitativo, ou seja, a descrição que resulta da observação e interpretação eficiente do professor sobre as manifestações do aluno e, que inclui a descrição do nível de compreensão do conteúdo em que se encontra esse aluno.

Segundo Melchior (1999:15), a avaliação da aprendizagem é importante para o aluno na medida em que ele pode tomar conhecimento das suas capacidades para futuras aprendizagens, bem como situar-se em relação ao que está sendo proposto. O fato de poder discutir os resultados obtidos propicia um bom relacionamento entre professor e aluno e entre os colegas, favorecendo a socialização, a autoconfiança e o respeito mútuo entre os participantes do processo.

Para o professor, a avaliação é importante porque, através dos resultados dos alunos, ele pode avaliar o seu desempenho, compreender melhor as formas de aprendizagem e o processo de ensino. "Assim a avaliação atingirá sua função didático-pedagógica de auxiliar o aprendiz e o professor a obterem eficácia no processo ensino e aprendizagem quando for conduzida de acordo com o seu verdadeiro significado" (Melchior, 1999:17).

Trataremos ainda de mais dois aspectos da avaliação, que a acadêmica percebeu que deveriam ser redimensionados por ela após as discussões realizadas ao final de cada ciclo e também do feedback proporcionado pelos alunos. O primeiro se refere aos critérios de avaliação e ao valor das questões da prova.

De acordo com Vasconcelos (2002:197) em pesquisa realizada com alunos universitários, entre os problemas de avaliação relatados por eles, encontram-se as situações em que o professor não esclarece quanto aos critérios, também não orienta quanto aos conteúdos a serem avaliados ou ainda elabora mal e de maneira confusa as questões da prova. Sobre este mesmo ponto Luckesi (1999: 172) opina que 
"dificilmente os professores definem com clareza, no ato do planejamento de ensino, qual é o padrão de qualidade que se espera da conduta do aluno, após ser submetido a uma determinada aprendizagem". Se o professor não tem claro nem para si mesmo o que espera do aluno, é previsível que não especifique para ele qual é o comportamento desejado. Para Vasconcelos (2002:197) esses problemas são também de âmbito comunicacional que envolvem o ato pedagógico e que deveriam reger a avaliação. Não raras vezes, a falta de uma comunicação adequada, provoca situações mal esclarecidas que resultam em prejuízo para o aluno.

Os conceitos da acadêmica em relação à não informação dos critérios e a avaliar em maior valor as questões que ela considerava mais difíceis, sem necessariamente estarem relacionadas aos objetivos do ensino provêm da sua experiência como aluna, num de seus diários ela justificou o seu comportamento dizendo "pois foi assim que eu sempre fui avaliada". Ela demonstra estar vivenciando na sua formação acadêmica uma situação semelhante a da maioria dos graduandos do sistema de ensino brasileiro.

Após discussões a respeito do processo avaliativo, a acadêmica S. percebeu que deveria esclarecer aos alunos com antecedência, quais os critérios que seriam usados como parâmetro de avaliação da prova e que o grau de dificuldade das questões deveria estar diretamente relacionado à forma como foi trabalhado em aula e aos objetivos a serem alcançados. De acordo com ela:

\footnotetext{
é muito melhor para o aluno saber antes em que pontos estará sendo avaliado, para que ele se sinta mais tranqüilo... é impossível exigir do aluno algo que não foi bem trabalhado ao longo do semestre...eu acredito, agora, que realmente a avaliação não deve ser um mistério ou até mesmo motivo para nervosismo".
}

A outra questão se refere à produção oral, que no needs analysis aplicado aos alunos no início do semestre foi considerada como prioridade, para a maioria deles, foi necessário, então, dar mais ênfase a ela e, conseqüentemente, passou a fazer parte do processo avaliativo. Porém, na mesma medida que alguns deles queriam melhorar o seu desempenho nesta habilidade, demonstravam grande dificuldade em expor-se perante a turma, talvez devido ao fato de que a turma é bastante heterogênea quanto ao nível de habilidade oral, favorecendo uma participação muito 
efetiva daqueles que se sentem mais seguros por dominarem mais a $L E$ e, a pouca participação dos outros.

Naturalmente eles se agrupavam de acordo com o nível de habilidade, levantamos a hipótese de que se os grupos fossem heterogêneos haveria um maior rendimento em aula, estimulando que eles se ajudassem mutuamente, também foi dada a oportunidade de expressarem-se primeiramente por escrito e em Português àqueles que se sentissem intimidados em falar e depois em dupla expressariam suas idéias em inglês. Além disso, quando estão trabalhando individualmente a professora oferece ajuda quanto ao vocabulário para que eles se sintam mais seguros ao falar. Eles foram incentivados a falar sem preocupar-se com os erros, porque essa seria a melhor forma da professora poder corrigi-los, e assim buscar um melhor desempenho.

A acadêmica relata nos diários um desempenho crescente desses alunos em aula, inclusive falando mesmo sem serem solicitados. "Todos foram participativos quando eu pedi que cada um desse sua opinião (...) esqueci de pedir para o aluno $\mathrm{A}$ falar e ele, voluntariamente, começou a dar a sua opinião. Isso me deixou muito contente..." Quando se cruza as informações dela com os questionários realizados com os alunos, eles dizem perceber que a professora mudou a sua metodologia, de acordo com eles, conforme a professora foi conhecendo melhor cada um deles, ela pôde adequar as atividades, dando oportunidade a todos de se expressarem sem se preocupar com os erros, acreditam que é muito positivo quando a professora corrige e dá a eles a oportunidade de sanar as dúvidas. Salientam que se sentem mais à vontade para falar em aula agora do que no início do semestre, porém quando foi pedido que expressassem através de metáforas, como se sentem quando têm que falar em aula, os mais tímidos dizem sentir-se como "um réu no julgamento", "uma lesma que anda e não sai do lugar" "não gosto de ser observado" percebe-se que ainda é muito forte neles a insegurança e o medo do insucesso, talvez conseqüência de anos de experiências negativas frente ao processo avaliativo, esse fato é ainda mais relevante considerando que eles são alunos de um curso livre de língua estrangeira e que uma reprovação não compromete a sua vida acadêmica e ou profissional. 


\section{BIBLIOGRAFIA}

FREUDENBERGER, Francieli e ROTTAVA, Lúcia. Crenças de professores:

natureza e origens. In: Formas e Linguagens. ljuí: Editora Unijuí, Abril/Junho 2002.

HOFFMANN, J. Avaliação Mediadora: uma prática em construção da pré-escola à Universidade. Porto Alegre: Mediação, 2000.

Avaliação: mito \& desafio: uma perspectiva construtivista. Porto Alegre:Mediação,1991.

Pontos e Contrapontos: do pensar ao agir em

avaliação. Porto Alegre: Mediação, 1998.

HYON, Sunny. Genre in three traditions: Implications for ESL. In: TESOL

Quaterly, Volume 30, Number 4, 1996.

KRAMSH, Claire. Language and culture. Oxford University Press, 1998

LUCKESI, C. C. A

Avaliação da Aprendizagem Escolar. São Paulo: Cortez,1999.

MARCUSCHI, Luis Antonio. Gêneros textuais: definição e funcionalidade. In: A P Dionísio; A. R. Machado;e M. A. Bezerra (orgs): Gêneros textuais \& Ensino. Rio de Janeiro: Lucerma, 2002.

MELCHIOR, M.C. Avaliação Pedagógica: função e necessidade. Porto Alegre:Mercado Aberto, 1999.

MORAN, Patrick R. Teaching Culture. Heinle \& Heinle, 2001.

VASCONCELLOS, M..M. Morita. Avaliação e Ética. Londrina:UEL, 2002. 